\title{
Expression of the Human NAD(P)-Metabolizing Ectoenzyme CD38 Compromises Systemic Acquired Resistance in Arabidopsis
}

\author{
Xudong Zhang and Zhonglin Mou \\ Department of Microbiology and Cell Science, University of Florida, P.O. Box 110700, Gainesville 32611, U.S.A. \\ Submitted 31 October 2011. Accepted 22 May 2012.
}

\begin{abstract}
Plant systemic acquired resistance (SAR) is a long-lasting, broad-spectrum immune response that is mounted after primary pathogen infection. Although SAR has been extensively researched, the molecular mechanisms underlying its activation have not been completely understood. We have previously shown that the electron carrier NAD(P) leaks into the plant extracellular compartment upon pathogen attack and that exogenous $\mathrm{NAD}(P)$ activates defense gene expression and disease resistance in local treated leaves, suggesting that extracellular $\mathrm{NAD}(\mathrm{P})[\mathrm{eNAD}(\mathrm{P})]$ might function as a signal molecule activating plant immune responses. To further establish the function of $\operatorname{eNAD}(P)$ in plant immunity, we tested the effect of exogenous NAD(P) on resistance gene-mediated hypersensitive response $(\mathrm{HR})$ and SAR. We found that exogenous NAD $(P)$ completely suppresses HR-mediated cell death but does not affect HRmediated disease resistance. Local application of exogenous NAD $(P)$ is unable to induce SAR in distal tissues, indicating that $\mathrm{eNAD}(\mathrm{P})$ is not a sufficient signal for SAR activation. Using transgenic Arabidopsis plants expressing the human NAD(P)-metabolizing ectoenzyme CD38, we demonstrated that altering eNAD $(P)$ concentration or signaling compromises biological induction of SAR. This result suggests that eNAD(P) may play a critical signaling role in activation of SAR.
\end{abstract}

Plants, like animals, are constantly subject to a wide variety of potentially dangerous microorganisms. To protect themselves from microbial invasion and colonization, plants have evolved a sophisticated immune system to detect the presence of microbes and to activate defense responses (Jones and Takemoto 2004). Plant cells can detect the presence of microbes by recognizing two general groups of pathogen-derived molecules. One group of such molecules is the so-called microbe- or pathogen-associated molecular patterns (MAMPs or PAMPs), which are conserved molecules characteristic of a whole class of microbes. The other group is the effector molecules that are delivered into the plant cell by the pathogen's type III secretion system (He 1998; Nurnberger et al. 2004). Recognition of PAMPs by PAMP receptors activates the so-called PAMPtriggered immunity (PTI) (Gomez-Gomez et al. 1999; Ron and Avni 2004). Pathogens can often overcome the PTI by delivering effector molecules into the plant cell to interfere with

Corresponding author: Z. Mou; Telephone: +1.352.392.0285; Fax: +1.352.392.5922; E-mail: zhlmou@ufl.edu

* The $e$-Xtra logo stands for "electronic extra" and indicates that six supplementary figures are published online.
PTI. Plant cells, in turn, detect the presence of the effectors by resistance $(\mathrm{R})$ proteins, inducing the so-called effector-triggered immunity (ETI) to restrict pathogen growth (Dangl and Jones 2001; Heath 2000; Martin et al. 2003). Both PTI and ETI contribute to the activation of a defense mechanism named systemic acquired resistance (SAR) in tissues distant from the primary infection site (Durrant and Dong 2004; Mishina and Zeier 2007; Ryals et al. 1996). Whereas it is generally accepted that SAR is activated by a blend of mobile signal molecules produced in the primarily infected tissues, the underlying molecular mechanisms are not entirely clear (Parker 2009; Vlot et al. 2008).

Pyridine nucleotide $\mathrm{NAD}(\mathrm{P})$ is a classic electron carrier that functions in metabolic reactions (Noctor et al. 2006) yet participates in both intracellular and extracellular signaling events (Berger et al. 2004). NAD(P) can be processed into the intracellular $\mathrm{Ca}^{2+}$-mobilizing agents cyclic ADP-ribose (cADPR) and nicotinic acid adenine dinucleotide phosphate (NAADP) that release $\mathrm{Ca}^{2+}$ from intracellular stores (Galione and Churchill 2000; Lee 2001). NAD also acts as an ADP-ribose donor and an acetyl group acceptor in protein ADP-ribosylation and deacetylation, respectively (Denu 2003). Upon environmental stress, cellular $\mathrm{NAD}(\mathrm{P})$ can be released into the extracellular compartment (ECC) by active exocytosis or diffusion through transmembrane transporters in living cells or passive leakage across membrane in dying cells (Billington et al. 2006b). In the $\mathrm{ECC}, \mathrm{NAD}(\mathrm{P})$ is processed by ectoenzymes or perceived by cell surface receptors or channels, activating downstream signaling pathways. A number of NAD(P)-metabolizing enzymes, including CD38 and mono(ADP-ribosyl)transferases (ART), have been identified on the extracellular surface of the plasma membrane (Malavasi et al. 2006; Morabito et al. 2006; Partida-Sanchez et al. 2007; Zolkiewska 2005). CD38 is a multifunctional enzyme combining ADP-ribosyl cyclase, cADPR-hydrolase, and NAD-hydrolase activities, which utilizes NAD $(P)$ as substrate to generate cADPR and NAADP (Ceni et al. 2003; Krebs et al. 2005; Partida-Sanchez et al. 2003). Both cADPR and NAADP can be transported across the plasma membrane to reach their intracellular targets and raise intracellular $\mathrm{Ca}^{2+}$ concentration $\left(\left[\mathrm{Ca}^{2+}\right]_{\mathrm{i}}\right.$ ) (Billington et al. 2006a; De Flora et al. 2004). NAD ${ }^{+}$and NAADP can also function in the ECC to activate purinoceptors, resulting in increases in $\left[\mathrm{Ca}^{2+}\right]_{\mathrm{i}}$ (Heidemann et al. 2005; Singaravelu and Deitmer 2006). ART are glycosylphosphatidylinositol-anchored or secreted ectoenzymes that use NAD to ADP-ribosylate purinoceptor, CD38, integrin, and other raft-associated signaling proteins, resulting in inhibition of CD38 and activation of purinoceptors (Bannas et al. 2005; Han et al. 2000; Nemoto et al. 1996; Seman et al. 2003). 
We have previously shown that, in Arabidopsis, exogenous application of NAD $(\mathrm{P})$ activates both defense gene expression and disease resistance, and we hypothesized that extracellular $\mathrm{NAD}(\mathrm{P})[\mathrm{eNAD}(\mathrm{P})]$ may be perceived by plant cells as a danger signal of pathogen attack, leading to the activation of immune responses (Zhang and Mou 2009). Although we reported that $\mathrm{NAD}(\mathrm{P})$ leaks into the ECC during pathogen infection, evidence supporting a role for endogenous eNAD(P) in plant immunity is still lacking. Here, in addition to testing the effect of exogenous $\mathrm{NAD}(\mathrm{P})$ on $R$-gene-mediated hypersensitive response (HR) and SAR, we expressed the human $\mathrm{NAD}(\mathrm{P})$ metabolizing ectoenzyme CD38 in Arabidopsis to manipulate the levels of endogenous eNAD(P). We used CD38 because no plant $\mathrm{NAD}(\mathrm{P})$-metabolizing ectoenzyme has been reported. Using the transgenic Arabidopsis plants expressing CD38, we provided evidence that eNAD $(\mathrm{P})$ may participate in the activation of SAR.

\section{RESULTS}

\section{Exogenous NAD(P) suppresses HR-mediated cell death but not HR-mediated disease resistance.}

To test whether exogenous NAD $(\mathrm{P})$ affects HR-mediated defense responses, we treated Arabidopsis plants with different concentrations of $\mathrm{NAD}^{+}$followed by inoculation of the bacterial pathogen Pseudomonas syringae pv. tomato DC3000 carrying the avrRpt2 gene (Pst/avrRpt2). Ion leakage was used to quantify HR-mediated cell death. Without NAD ${ }^{+}$pretreatment, PstlavrRpt2 induced a significant ion leakage (Supplementary Fig. S1), whereas the negative control $\left(10 \mathrm{mM} \mathrm{MgCl}{ }_{2}\right.$ treatment) did not result in a strong ion leakage. Interestingly, $\mathrm{NAD}^{+}$pretreatment inhibited Pst/avrRpt2-induced ion leakage in a concentration-dependent manner. We previously have shown that the amount of $\mathrm{NAD}(\mathrm{P})$ leaking into the ECC after Pst/avrRpt2 infection is comparable with that after infiltration with $1 \mathrm{mM} \mathrm{NAD(P)} \mathrm{(Zhang} \mathrm{and} \mathrm{Mou} \mathrm{2009);} \mathrm{therefore,} \mathrm{we}$ used this concentration in the experiment.

Pretreatment of Arabidopsis plants with $1 \mathrm{mM} \mathrm{NAD}^{+}$or 1 mM NADP ${ }^{+}$completely suppressed Pst/avrRpt2- and Pst/ avrRps4-induced leaf collapse (Fig. 1A and B). These pretreatments also significantly suppressed Pst/avrRpt2- and Pst/avrRps4-induced ion leakage (Fig. 1C and D). Because HR-mediated cell death is generally associated with resistance (Coll et al. 2011; Mur et al. 2008), we tested whether NAD(P) also suppresses HR-mediated disease resistance. Wild-type Col-0 plants were treated with $1 \mathrm{mM} \mathrm{NAD}^{+}$or $1 \mathrm{mM} \mathrm{NADP}^{+}$ followed by inoculation of Pst/avrRpt 2 or Pst/avrRps4. $\mathrm{MgCl}_{2}$ pretreatment was included as a negative control. The fully susceptible mutants rps2 (for Pst/avrRpt2) and rps4 (for Pst/ avrRps4) were also included as controls in the experiment. Consistent with the previous observations (Kunkel et al. 1993; Wirthmueller et al. 2007), rps2 and rps4 were highly susceptible to PstlavrRpt2 and Pst/avrRps4, respectively, and HR-mediated resistance significantly inhibited the growth of Pst/avrRpt2 and PstlavrRps4 in the $\mathrm{MgCl}_{2}$-pretreated plants (Fig. $1 \mathrm{E}$ and F). Surprisingly, although $\mathrm{NAD}(\mathrm{P})^{+}$suppressed HR-mediated cell death, the growth of Pst/avrRpt2 and Pst/avrRps4 in $\mathrm{NAD}(\mathrm{P})^{+}$-pretreated plants was comparable with that in $\mathrm{MgCl}_{2-}$ pretreated plants (Fig. 1E and $\mathrm{F}$ ). These results indicate that exogenous $\mathrm{NAD}(\mathrm{P})$ suppresses HR-mediated cell death but does not compromise HR-mediated resistance. To test whether exogenous $\mathrm{NAD}(\mathrm{P})$-induced resistance depends on $R$ genes, we treated rps 2 and rps 4 with $1 \mathrm{mM} \mathrm{NAD}^{+}$followed by inoculation of Pst/avrRpt 2 and Pst/avrRps4, respectively. NAD ${ }^{+}$ pretreatment significantly inhibited the growth of both Pst/ avrRpt2 and Pst/avrRps4 (Supplementary Fig. S2), though the effect of inhibition on Pst/avrRps4 was stronger than that on Pst/avrRpt2. These results suggest that exogenous NAD(P) mainly activates $R$-gene-independent disease resistance in Arabidopsis.

\section{Local application of exogenous NAD(P) does not induce SAR.}

After being released into the $\mathrm{ECC}, \mathrm{NAD}(\mathrm{P})$ or its derivatives may function as a mobile signal to induce $S A R$ in the distal tissues. To test this hypothesis, we infiltrated three lower leaves on each plant with different concentrations of $\mathrm{NAD}(\mathrm{P})$. Adenosine triphosphate (ATP) was included as a control in the experiment. After three days, the upper leaves were inoculated with the virulent bacterial pathogen $P$. syringae pv. maculicola ES4326. The in planta growth of ES4326 was determined 3 days later. A concentration of $5 \mathrm{mM} N A D(H)$ induced a significant SAR (Fig. 2A), though much weaker than that induced by PstlavrRpt2. However, when a physiologically relevant concentration (1 mM) was used (Zhang and Mou 2009), none of the five chemicals $\left(\mathrm{NAD}^{+}, \mathrm{NADH}, \mathrm{NADP}^{+}, \mathrm{NADPH}\right.$, and ATP) induced a significant SAR. Therefore, under physiological conditions, eNAD(P) (or its derivatives) may not be a sufficient signal for activating SAR.

\section{CD38 is localized at the plasma membrane in transgenic Arabidopsis.}

To establish a more direct relationship between eNAD(P) and plant immunity, we wished to express a protein that could alter the concentration of eNAD(P) or its signaling in Arabidopsis plants. Due to the lack of any known NAD(P)-metabolizing ectoenzyme in plants, we chose the well-characterized human protein $\mathrm{CD} 38$, an integral membrane protein with its enzyme-active site on the extracellular surface of the plasma membrane (Deaglio and Malavasi 2006). In human cells, CD38 metabolizes eNAD(P) to the secondary messengers cADPR and NAADP, which activate transmembrane signaling (Billington et al. 2006a; De Flora et al. 2004; Partida-Sanchez et al. 2003). Although the function of extracellular NAADP in plant immunity has not been defined, cADPR has been shown to induce phenylalanine ammonia lyase and pathogenesisrelated $(P R) l$ expression in tobacco leaf disks (Durner et al. 1998). We expected that expression of CD38 in plants would modify eNAD(P)-activated immune responses.

In human cells, CD38 is localized in the plasma membrane (Malavasi et al. 2008). To test whether CD38 is correctly localized in transgenic plants, we used the green fluorescence protein (GFP) as a reporter. The GFP coding region was fused to the $3^{\prime}$ end of the CD38 cDNA, and the expression of the CD38-GFP fusion gene is under the control of the constitutive Cauliflower mosaic virus $35 \mathrm{~S}$ promoter (Odell et al. 1985). To generate a construct expressing an inactive form of CD38, we introduced a point mutation into the $35 S:: C D 38-G F P$ construct to change the glutamate residue at the active site, Glu226, to glycine (named hereafter E226G) (Munshi et al. 2000). Both constructs (35S::CD38-GFP and 35S::E226G-GFP) were transformed into wild-type Col-0 plants. Transgenic lines were screened by protein gel-blot analysis using a monoclonal anti-GFP antibody, and those lines expressing CD38-GFP or E226G-GFP were used for further subcellular localization study.

The subcellular localization of CD38-GFP was examined by confocal microscopy. Plants expressing GFP alone were included as a control in the experiment. GFP was localized in the cytosol, whereas both CD38-GFP and E226G-GFP were localized predominantly in an area corresponding to the plasma membrane (Fig. 3). In order to visualize the plasma membrane better, the Arabidopsis root cells were plasmolyzed. After plasmolysis, both CD38-GFP and E226G-GFP appeared to be 
A

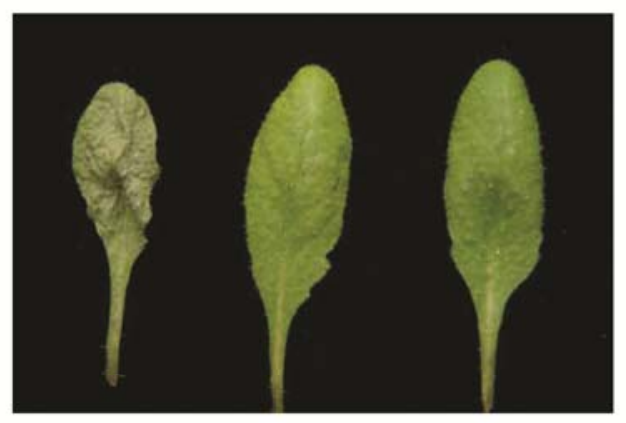

$\begin{array}{lll}\mathrm{MgCl}_{2} & \mathrm{NAD}^{+} \quad \mathrm{NADP}^{+}\end{array}$

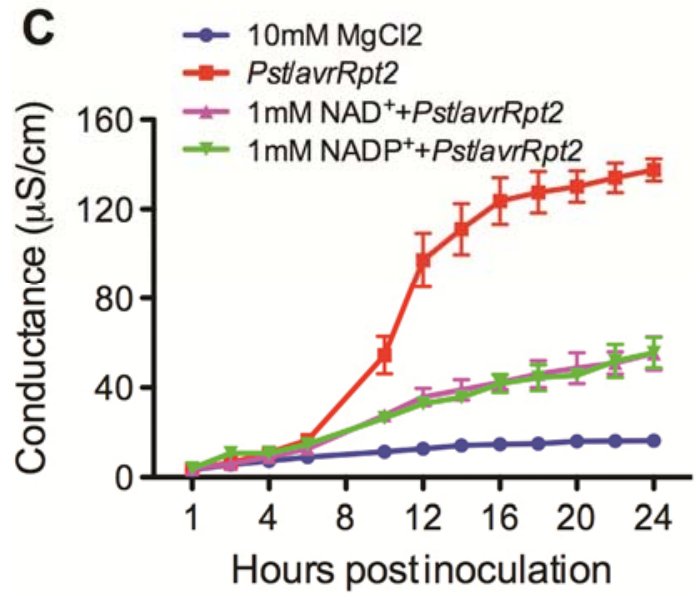

E Growth of PstlavrRpt2

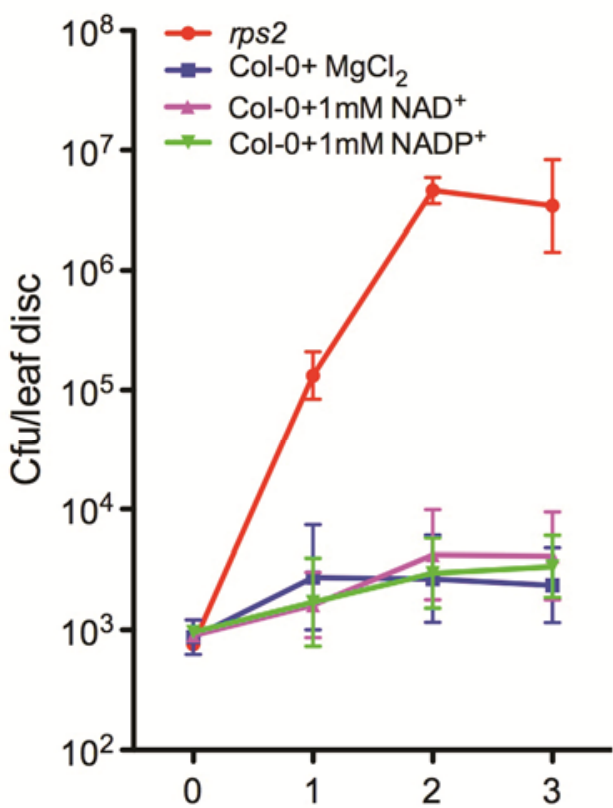

Days postinoculation
B

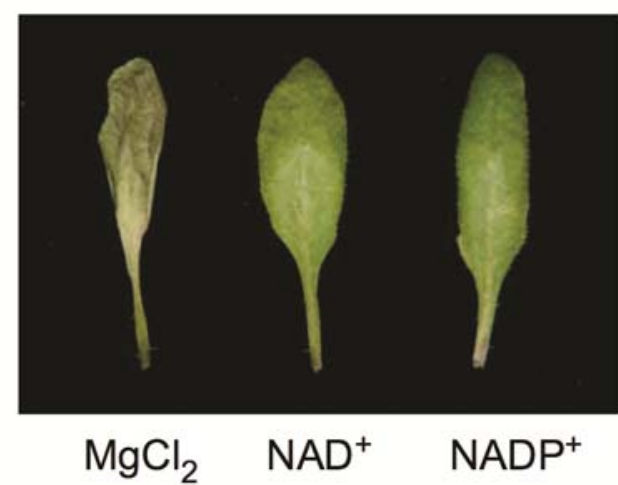

D

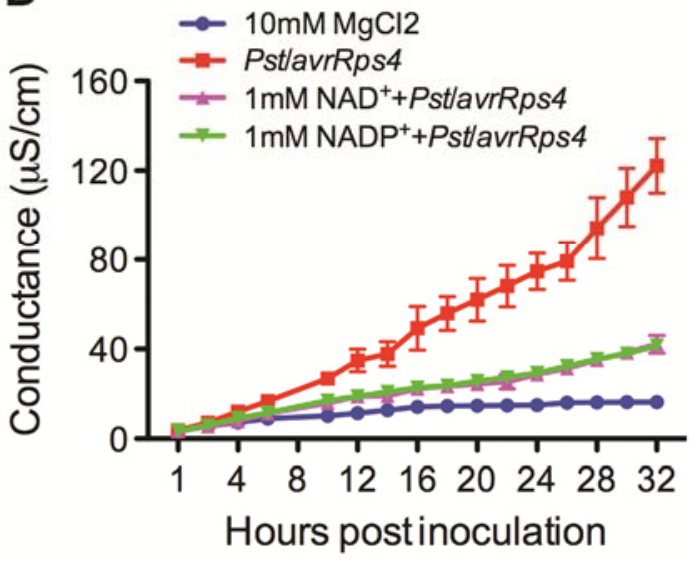

$\mathbf{F}$

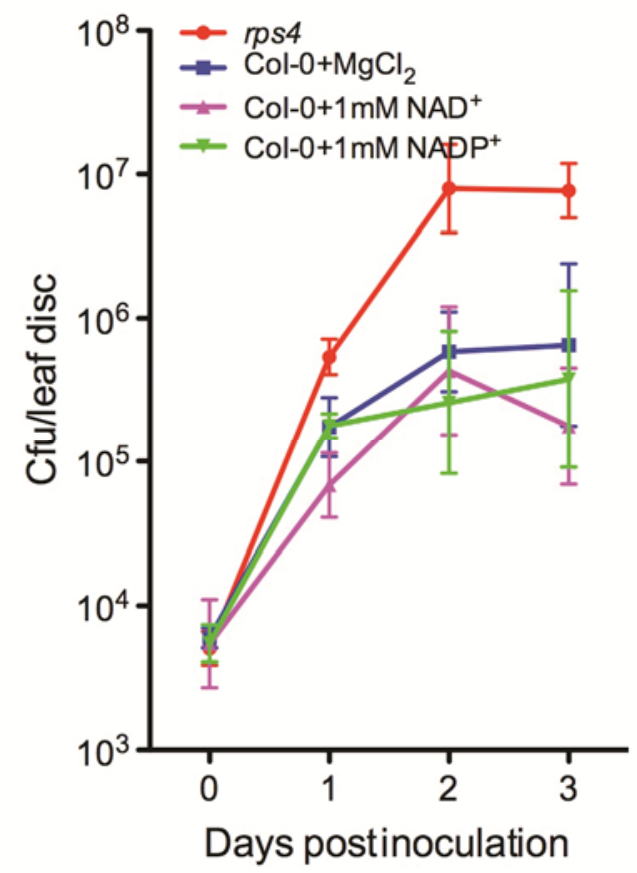

Fig. 1. Effect of exogenous $\mathrm{NAD}(\mathrm{P})$ on hypersensitive-response-mediated cell death and resistance. A, Wild-type Col-0 leaves pretreated with 10 mM $\mathrm{MgCl}_{2}, 1 \mathrm{mM} \mathrm{NAD}{ }^{+}$, or $1 \mathrm{mM}$ NADP ${ }^{+}$followed by inoculation with the avirulent bacterial pathogen Pst/avrRpt 2 . B, Wild-type Col-0 leaves pretreated with $10 \mathrm{mM} \mathrm{MgCl}_{2}, 1 \mathrm{mM} \mathrm{NAD}$, or $1 \mathrm{mM} \mathrm{NADP}^{+}$followed by inoculation with the avirulent bacterial pathogen Pst/avrRps4. C, Ion leakage from wild-type

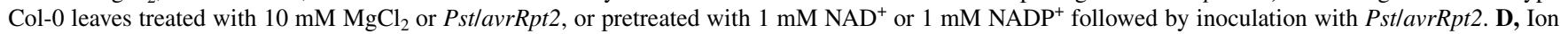
leakage from wild-type Col-0 leaves treated with $10 \mathrm{mM} \mathrm{MgCl}_{2}$ or Pst/avrRps4, or pretreated with $1 \mathrm{mM} \mathrm{NAD}^{+}$or $1 \mathrm{mM} \mathrm{NADP}{ }^{+}$followed by inoculation with Pst/avrRps4. E, Growth of Pst/avrRpt 2 in rps 2 and wild-type Col-0 plants pretreated with $10 \mathrm{mM} \mathrm{MgCl}_{2}, 1 \mathrm{mM} \mathrm{NAD} \mathrm{mM}^{+}$, $1 \mathrm{mM} \mathrm{NADP}$. F, Growth of PstlavrRps 4 in rps 4 and wild-type Col-0 plants pretreated with $10 \mathrm{mM} \mathrm{MgCl}_{2}, 1 \mathrm{mM} \mathrm{NAD} \mathrm{N}^{+}$, or $1 \mathrm{mM} \mathrm{NADP}{ }^{+}$. Error bars represent standard deviation. Experiments were repeated three times with similar results. 
localized in the plasma membrane and not in the cell wall (Fig. 3). To confirm the plasma membrane localization of CD38-GFP, we produced protoplasts by digesting the cell wall of the root cells expressing CD38-GFP. Whereas GFP alone was localized in the cytosol of the cell, CD38-GFP and E226G-GFP were strictly localized to the plasma membrane of the cell in a nonhomogeneous pattern (Fig. 3). To further confirm that CD38-GFP is localized in the plasma membrane, we separated total membranes from soluble fractions by membrane fractionation. CD38-GFP and E226G-GFP were present in the membrane fraction but not in the soluble supernatant (Supplementary Fig. S3A). We also measured total NAD(P) levels in Col-0, 35S::CD38-GFP, and $35 S::$ E226G-GFP plants using both denatured (heated at $95^{\circ} \mathrm{C}$ for $5 \mathrm{~min}$ ) and undenatured samples. We reasoned that, if CD38GFP is localized in the plasma membrane and functions as an NAD(P)-metabolizing ectoenzyme, it should change the total NAD $(P)$ levels in undenatured samples but not in denatured samples. Total NAD $(\mathrm{P})$ levels were similar in the denatured samples from all genotypes, whereas NADP levels were significantly lower and NAD levels were also lower in the undenatured samples from the $35 S:: C D 38-G F P$ plants than in those from the wild-type Col-0 and $35 S:: E 226 G-G F P$ plants. Taken together, these results clearly demonstrate that CD38 is localized in the plasma membrane when expressed in plant cells.

\section{Expression of CD38 suppresses exogenous NAD(P)-induced} $P R$ gene expression and disease resistance.

After showing that both CD38-GFP and E226G-GFP are localized in the plasma membrane in transgenic Arabidopsis, we were able to test whether CD38 functions in plants using the transgenic plants. We also generated $35 S:: C D 38$ transgenic plants in case fusion of CD38 with GFP affects CD38 activity. We expected that transgenic Arabidopsis expressing the active form of $\mathrm{CD} 38$ would exhibit altered responses to $\operatorname{eNAD}(\mathrm{P})$ no matter whether plants and animals employ similar mechanisms to perceive eNAD $(\mathrm{P})$.

We first tested the induction of $P R I$ gene expression by different concentrations of exogenous $\mathrm{NAD}^{+}$in the transgenic plants. Consistent with our previous observation (Zhang and Mou 2009), PRl was induced by $\mathrm{NAD}^{+}$in a concentrationdependent manner (Fig. 4A). Intriguingly, induction of $P R 1$ gene expression by exogenous $\mathrm{NAD}^{+}$at a concentration of 1 $\mathrm{mM}$ or lower was completely blocked in both the $35 S: \because C D 38$ and $35 S:: C D 38-G F P$ plants, whereas induction of $P R 1$ expression in the $35 S:: E 226 G-G F P$ plants by exogenous NAD ${ }^{+}$ was comparable with that in the wild-type Col-0 plants. We noticed that the induction of $P R 1$ gene expression by exogenous $\mathrm{NAD}^{+}$was significantly decreased in a total of 29 independent $35 S:: C D 38$ transgenic lines, though the induction of $P R 1$ was not tightly correlated with the expression levels of CD38 (Supplementary Fig. S4). These results indicate that CD38 blocks eNAD $(\mathrm{P})$ signaling for $P R$ gene induction and that the enzyme-active site of CD38 is required for suppressing exogenous $\mathrm{NAD}^{+}$-induced $P R l$ gene expression.

We then tested $\mathrm{NAD}^{+}$-induced disease resistance in the transgenic plants. For this purpose, lower concentrations $(0.2$ and $0.4 \mathrm{mM}$ ) of exogenous $\mathrm{NAD}^{+}$were used because these concentrations are sufficient to induce strong disease resistance in wild-type Col-0 plants (Fig. 4B) (Zhang and Mou 2009). Induction of disease resistance in both the $35 S:: C D 38$ and $35 S: \because C D 38-G F P$ plants was significantly suppressed but not affected in the $35 S:: E 226 G-G F P$ plants, suggesting that CD38 suppresses $\mathrm{NAD}^{+}$-induced disease resistance and that the enzyme-active site of CD38 is required for suppressing exogenous $\mathrm{NAD}^{+}$-induced disease resistance.
Expression of CD38 depletes extracellular NAD(P).

Expression of the human ectoenzyme CD38 in plants suppresses exogenous $\mathrm{NAD}^{+}$-induced immune responses, suggesting that CD38 may metabolize the exogenously applied NAD ${ }^{+}$. To test whether CD38 metabolizes the endogenous eNAD(P) accumulated during pathogen infection, we measured NAD $(\mathrm{P})$ concentrations in the extracellular washing fluid (EWF) collected from pathogen-infected leaves of the wild-type Col-0 and the transgenic plants. Consistent with our previous observation (Zhang and Mou 2009), NAD(P) leaked into the ECC after the Pst/avrRpt2 infection (Fig. 5). Interestingly, the concentrations of NADP in the EWF collected from the Pst/ avrRpt2-infected $35 S:: C D 38$ or $35 S:: C D 38-G F P$ leaves were significantly lower than those from the wild-type Col-0 or $35 S:: E 226 G$-GFP leaves (Fig. 5A), whereas the concentrations of NAD in the EWF from the Pst/avrRpt2-infected $35 S:: C D 38$ or $35 S:: C D 38-G F P$ leaves were only slightly lower than those from the wild-type Col-0 or $35 S: \because E 226 G$ -
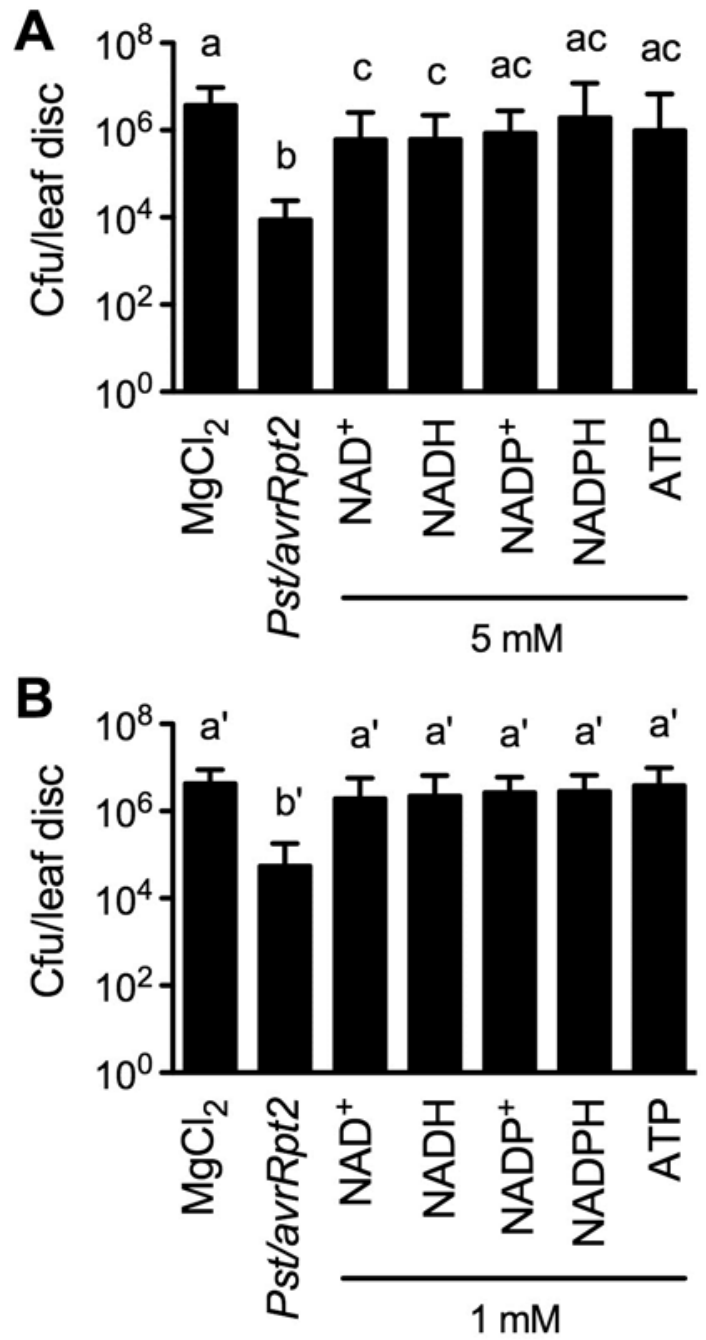

Fig. 2. Induction of systemic acquired resistance by local application of exogenous NAD(P). A, Growth of Pseudomonas syringae pv. maculicola ES4326 in the systemic leaves of wild-type Col-0 plants with lower leaves treated with $10 \mathrm{mM} \mathrm{MgCl}_{2}$, Pst/avrRpt2, $5 \mathrm{mM} \mathrm{NAD}^{+}, 5 \mathrm{mM} \mathrm{NADH}, 5$ mM NADP ${ }^{+}, 5 \mathrm{mM}$ NADPH, and $5 \mathrm{mM}$ adenosine triphosphate (ATP). B, Growth of $P$. syringae pv. maculicola ES4326 in the systemic leaves of wild-type Col-0 plants with lower leaves treated with $10 \mathrm{mM} \mathrm{MgCl}_{2}$, Pst/avrRpt 2, $1 \mathrm{mM} \mathrm{NAD}^{+}, 1 \mathrm{mM}$ NADH, $1 \mathrm{mM} \mathrm{NADP}{ }^{+}, 1 \mathrm{mM}$ NADPH, and $1 \mathrm{mM}$ ATP. Error bars represent standard deviation, and different letters above the bars indicate significant differences $(P<0.05, t$ test $)$. Experiments were repeated three times with similar results. 
GFP leaves (Fig. 5B). Although CD38 appears to have a stronger effect on eNADP than on eNAD, these results indicate that $\mathrm{CD} 38$ does, indeed, metabolize the $\mathrm{NAD}(\mathrm{P})$ released into the ECC during pathogen infection.

\section{Expression of CD38 compromises biological induction of SAR.}

Although eNAD(P) is not a sufficient mobile signal molecule for SAR activation, it may participate in mounting SAR through interaction with other signal molecules. To test this hypothesis, we investigated the biological induction of SAR in $35 S: \because C D 38,35 S:: C D 38-G F P, 35 S: \because E 226 G-G F P$, and wildtype Col-0 plants. Three lower leaves on each plant were infected with the avirulent bacterial pathogen Pst/avrRpt2. The upper uninfected leaves were either collected after 2 days for $P R$ gene analysis or inoculated after 3 days with the virulent bacterial pathogen $P$. syringae pv. maculicola ES4326, and the in planta growth of ES4326 was determined 3 days later. The induction of $P R 1, P R 2$, and $P R 5$ in the upper uninfected leaves of the $35 S:: C D 38$ and $35 S:: C D 38-G F P$ plants was decreased compared with that in the $35 S: \because E 226 G-G F P$ and Col-0 plants (Fig. 6A). Whereas the Pst/avrRpt2-induced SAR resistance to ES4326 was strong and comparable in the $35 S:: E 226 G-G F P$ and Col-0 plants, the induction of SAR resistance by PstlavrRpt2 was significantly inhibited in both the $35 S:: C D 38$ and $35 S:: C D 38-G F P$ plants (Fig. 6B). These results indicate that eNAD $(\mathrm{P})$ is positively involved in the biological induction of SAR. Because CD38 is an NAD(P)-metabolizing ectoenzyme which converts extracellular NAD and NADP to cADPR and NAADP, respectively, SAR induction in $35 S:: C D 38$ and $35 S:: C D 38-G F P$ plants might be inhibited by cADPR or NAADP. To test this possibility, we treated lower leaves with cADPR or NAADP prior to Pst/avrRpt2 inoculation for SAR induction. cADPR and NAADP did not significantly affect Pst/avrRpt2-induced SAR resistance (Supplementary Fig. S5), indicating that CD38 may inhibit biological induction of SAR through reduction of eNAD(P) levels.

\section{DISCUSSION}

SAR is a secondary immune response activated in the distal parts of a plant by mobile signal molecules generated in the primarily infected tissues. SAR confers long-lasting resistance to subsequent infections by a broad spectrum of pathogens (Durrant and Dong 2004). It is generally believed that multiple mobile signal molecules coexist but the nature and action mode of the signal molecules remain controversial (Attaran et al. 2009; Chaturvedi et al. 2008; Parker 2009). Evidence thus far has indicated that reactive oxygen species, methyl-salicylic acid, jasmonic acid, azelaic acid, and glycerol-3-phosphate (G3P) are likely mobile signal molecules activating SAR (Alvarez et al. 1998; Chanda et al. 2011; Jung et al. 2009; Park et al. 2007; Truman et al. 2007). Our data suggest that eNAD(P) may play an important signaling role in the activation of SAR.

$\mathrm{NAD}(\mathrm{P})$ is usually found inside the cell acting as an electron carrier in metabolic reactions or participating in intracellular signaling events unrelated to metabolism (Berger et al. 2004). However, it is known that certain animal cells actively release NAD(P) into the ECC upon stimulation or passively leak out NAD $(P)$ during cell death and inflammation (Bruzzone et al. 2001; Contreras et al. 2003; Smyth et al. 2004). In the ECC, $\mathrm{NAD}(\mathrm{P})$ are perceived or processed on the adjacent cell plasma membrane via distinct mechanisms. NAD and NADP can be metabolized by the ectoenzyme CD38 to cADPR and NAADP, respectively, which, in turn, move across the plasma membrane and trigger intracellular signaling events (Billington et al. 2006a; De Flora et al. 2004). NAD(P) can also act di- rectly on plasma membrane receptors and NAD can be utilized to ADP-ribosylate plasma membrane receptors (Bannas et al. 2005; Han et al. 2000; Judkins et al. 2006; Moreschi et al. 2006; Nemoto et al. 1996; Seman et al. 2003). To test whether similar mechanisms are evolved in plants, we generated Arabidopsis transgenic plants expressing the human CD38 protein that metabolizes NAD and NADP to cADPR and NAADP, respectively. As in human cells, CD38 is localized in the plasma membrane in the transgenic plants (Fig. 3), which is in agreement with its ectoenzyme character (Malavasi et al. 2006; Morabito et al. 2006). Interestingly, we found that expression of $\mathrm{CD} 38$ inhibited exogenous NAD(P)-induced immune responses and that the enzyme-active site of CD38 is required for the inhibition (Fig. 4), suggesting that the human ectoenzyme CD38 is active when expressed in Arabidopsis. Consistently, we detected less NAD and significantly less NADP in the EWF collected from pathogen-infected leaves of the transgenic plants expressing the active form of CD38 than in the EWF from wild-type or transgenic plants expressing the inactive form of CD38 (Fig. 5). These results suggest that, although the human ectoenzyme CD38 can process eNAD(P) in the plant ECC, the resulting secondary messengers cADPR and NAADP may not be able to activate immune responses. Thus, plants and animals may use different mechanisms to process eNAD(P) for immunity activation, though it is possible that, in plants, CD38-generated cADPR and NAADP trigger some signaling pathways other than immune response. Whether, in plants, eNAD $(\mathrm{P})$ could act directly on plasma membrane receptors requires further investigation.

We have shown that exogenous $\mathrm{NAD}(\mathrm{P})$ induces salicylic acid (SA)- and NPR1-dependent $P R$ gene expression and disease resistance in local treated leaves (Zhang and Mou 2009), indicating that exogenous $\mathrm{NAD}(\mathrm{P})$ induces signaling pathways similar to those activated during SAR. Previous studies showed that preexisting SAR suppresses HR-mediated cell death (Devadas and Raina 2002; Rate and Greenberg 2001). Pretreatment of plants with exogenous NAD(P) induces SAR signaling pathways and, thus, also suppresses HR-mediated cell death (Fig. 1A-D). NAD(P) released into the ECC from the dying cells during HR does not have a strong effect on the HR-mediated cell death, because $\operatorname{eNAD}(\mathrm{P})$ accumulates after cell death occurs. However, eNAD(P) accumulated during HR might contribute to preventing the spread of HR-mediated cell death to the adjacent healthy cells. Because exogenous $\mathrm{NAD}(\mathrm{P})$-induced disease resistance to two avirulent bacterial pathogens is largely independent of their corresponding $R$ genes, it will be interesting to identify the signaling components downstream of eNAD $(\mathrm{P})$.

The transgenic Arabidopsis plants expressing the human ectoenzyme CD38 allowed us to assess the function of eNAD $(P)$ in defense gene induction, HR, basal resistance, and SAR. We found that SA- and Pst/avrRpt2-induced PRI expression, Pst/avrRpt2-induced HR (macroscopic leaf collapse), and basal resistance to Pst/avrRpt2 and P. syringae pv. maculicola ES4326 were not altered in the CD38 transgenic plants (Supplementary Fig. S6), suggesting that depleting eNAD(P) by $\mathrm{CD} 38$ in the transgenic plants may not influence defense responses in the primarily infected tissues. We are unable to conclude that eNAD(P) does not play a role in the defense of primarily infected tissues, because CD38 cannot completely remove eNAD(P) from the ECC. Surprisingly, we found that biological induction of SAR was significantly inhibited in the transgenic plants expressing the active form of CD38 but not in the transgenic plants expressing the inactive form of CD38 (Fig. 6). This result indicates that depleting eNAD $(\mathrm{P})$ accumulated in the primarily infected tissues prevents SAR induction. However, local application of a 
physiological concentration of $\mathrm{NAD}(\mathrm{P})$ did not induce SAR in systemic leaves (Fig. 2B), suggesting that eNAD(P) alone is not sufficient for activation of SAR. This is reminiscent of the signal molecule SA, which activates SAR signaling path- ways in local treated leaves but does not induce SAR in systemic leaves. Whereas SA accumulation is required for both basal resistance and SAR, removal of eNAD $(\mathrm{P})$ by expression of the human ectoenzyme CD38 only affects SAR in-

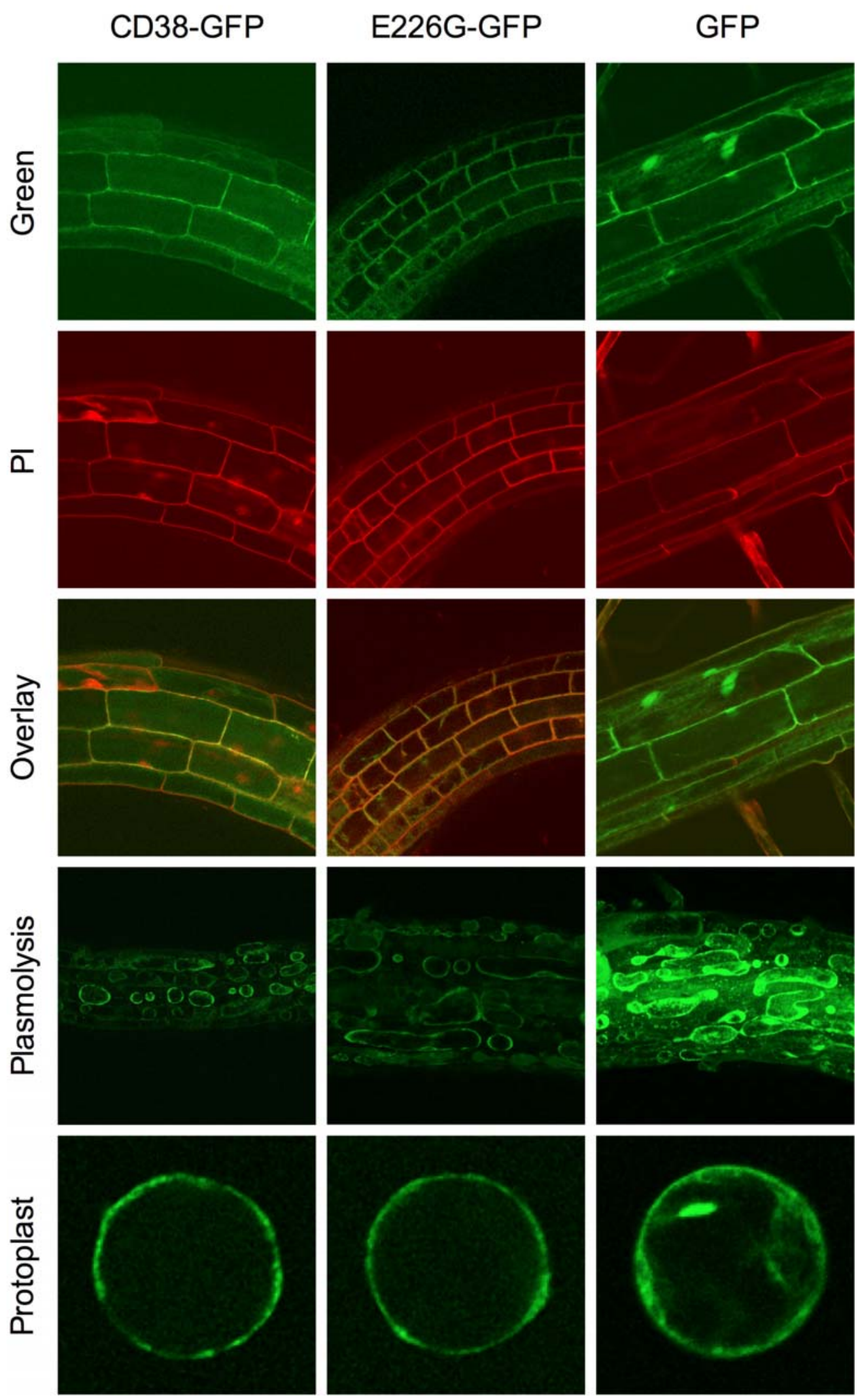

Fig. 3. Subcellular localization of green fluorescent protein (GFP), CD38-GFP, and E226G-GFP. GFP images, propidium iodide (PI) staining images, and overlays are shown in the top, second, and third row, respectively. GFP images of plasmolyzed cells and protoplasts are shown in the fourth and the bottom row, respectively. 
duction, suggesting that eNAD(P) accumulated after primary infection may play a more important role in the activation of SAR, a secondary immune response. It is possible that eNAD $(\mathrm{P})$ functions together with other signal molecules, or that a transporter is required for translocation of eNAD $(\mathrm{P})$ or its derivatives to distal tissues. The latter scenario has recently been observed for the likely SAR mobile signal molecule G3P, which requires the lipid transfer protein DIR1 for activating SAR (Chanda et al. 2011).

The nucleotide ATP has been shown to function in plant ECC as a modulator of cell death and pathogen defense (Chivasa et al. 2005, 2009). Extracellular ATP (eATP) and eNAD $(\mathrm{P})$ appear to play opposite functions in regulating plant immunity. Whereas eATP negatively regulates both cell death and defense response (Chivasa et al. 2005, 2009), eNAD(P) seems to suppress HR-mediated cell death but activate defense response (Fig. 1). Whereas exogenous application of ATP inhibits SA biosynthesis, $P R$ gene expression, and disease resistance (Chivasa et al. 2009), exogenous NAD(P) induces all these immune responses (Zhang and Mou 2009). The antagonistic relationship between eATP and $\operatorname{eNAD}(\mathrm{P})$ in regulating plant immunity deserves more detailed investigation.

Research in animal cells has established $\operatorname{eNAD}(\mathrm{P})$ as a signal molecule in activating intracellular signaling events, including immune responses (Billington et al. 2006b). Our data indicate that eNAD $(\mathrm{P})$ may also function as a signal molecule in plant immune responses (Zhang and Mou 2009). Although it is not clear whether plants employ mechanisms similar to those found in animal cells to process and perceive eNAD(P), results from characterization of Arabidopsis transgenic plants expressing the human ectoenzyme CD38 suggested otherwise. Thus far, no proteins similar to animal NAD(P)-utilizing ectoenzymes and cell surface receptors have been identified in plants (Sanchez et al. 2004; Zolkiewska 2005). Future studies will need to combine genetic and biochemical approaches to uncovering the identities of plant $\mathrm{eNAD}(\mathrm{P})$ receptors and downstream components of the eNAD $(\mathrm{P})$ signaling pathway (Zhang and Mou 2008). It is also desired to establish connections between the eNAD(P) signaling pathway and other wellcharacterized defense signaling pathways in plants.

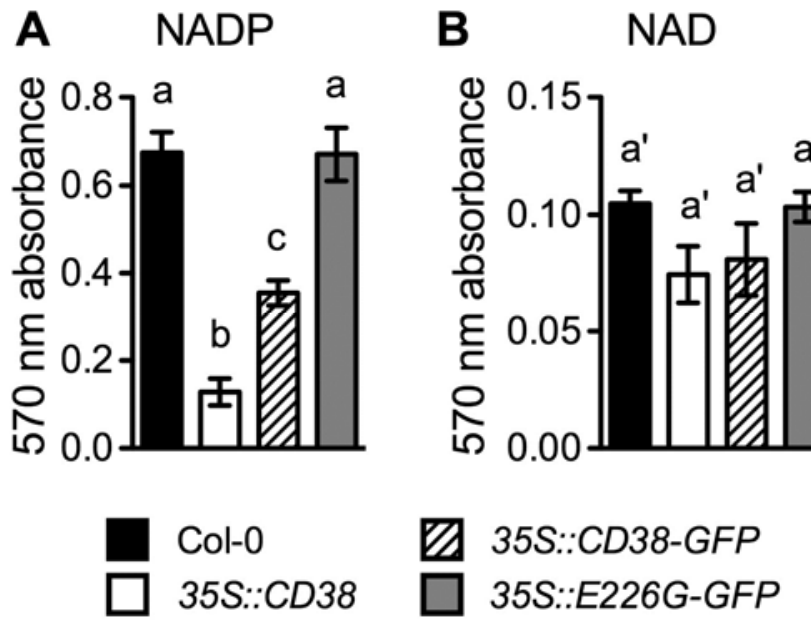

Fig. 5. Depletion of extracellular NAD(P) by CD38. A, NADP levels in extracellular washing fluids collected from wild-type Col-0, 35S::CD38, $35 S:: C D 38-G F P$, and $35 S:: E 226 G-G F P$ leaves infected with Pst/avrRpt2. $\mathbf{B}$, NAD levels in extracellular washing fluids collected from wild-type Col-0, 35S::CD38, 35S::CD38-GFP, and 35S::E226G-GFP leaves infected with Pst/avrRpt2. Error bars represent standard deviation, and different letters above the bars indicate significant differences $(P<0.05, t$ test). Experiments were repeated three times with similar results.
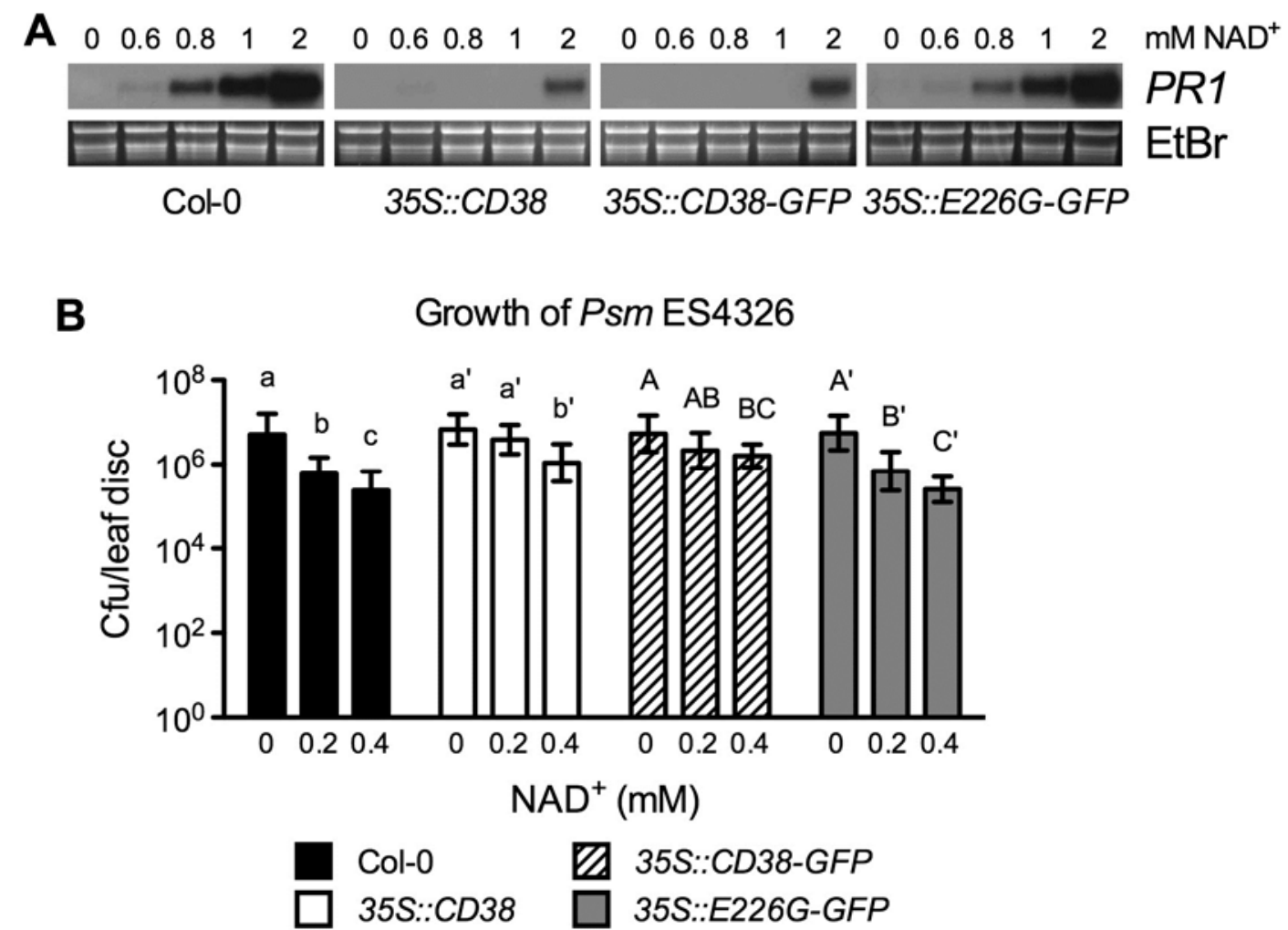

Fig. 4. Suppression of exogenous NAD(P)-induced immune responses by CD38. A, Induction of $P R 1$ gene expression by different concentrations of exogenous NAD ${ }^{+}$in wild-type Col-0, 35S::CD38, 35S::CD38-GFP, and 35S::E226G-GFP plants. The experiment was repeated with similar results. B, Growth of Pseudomonas syringae pv. maculicola ES4326 in Col-0, 35S::CD38, 35S::CD38-GFP, and 35S::E226G-GFP plants with or without NAD ${ }^{+}(0.2$ or $0.4 \mathrm{mM})$ pretreatment. Error bars represent standard deviation, and different letters above the bars indicate significant differences $(P<0.05, t$ test). The experiment was repeated three times with similar results. 


\section{MATERIALS AND METHODS}

Plant materials and growth conditions.

The wild type used was the Columbia ecotype (Col-0). Arabidopsis seed were sown on autoclaved soil (Metro-Mix 200; Grace-Sierra, Malpitas, CA, U.S.A.) and vernalized at $4^{\circ} \mathrm{C}$ for 3 days. Plants were germinated and grown at 23 to $25^{\circ} \mathrm{C}$ under a regime of $16 \mathrm{~h}$ of light and $8 \mathrm{~h}$ of darkness.

\section{Plasmid construction and plant transformation.}

A pair of primers-Xho I-CD38F1 (5'-CCGCTCGAGATG GCCAACTGCGAGTTCAG-3') and Nco I-CD38R (5'-CATG CCATGGCGATCTCAGATGTGCAAGATG-3') — was used to amplify the coding region of $C D 38$ from the cDNA clone of CD38 (provided by A. Yen, Cornell University). The polymerase chain reaction (PCR) products were digested with XhoI and $N c o I$ and then ligated into the corresponding sites of the vector pRTL2-mGFP, resulting in the plasmid pRTL2-CD38GFP. Then, the $35 S:: C D 38-G F P$ cassette was recovered using HindIII and subcloned into HindIII-digested and calf-intestinal alkaline phosphatase-treated pCB302 to generate the plasmid pCB302-35S::CD38-GFP. Site-directed mutagenesis of the amino acid residue (E226) at the active site of CD38 was performed in the pCB302-35S::CD38-GFP construct using a PCR-based Quick-Change site-directed mutagenesis kit (Stratagene, La Jolla, CA, U.S.A.). The primers used for the sitedirected mutagenesis were $C D 38 M u F$ (5'-CACTTTTGGGAG TGTGGGAGTCCATAATTTGCAAC-3') and CD38MuR (5'-
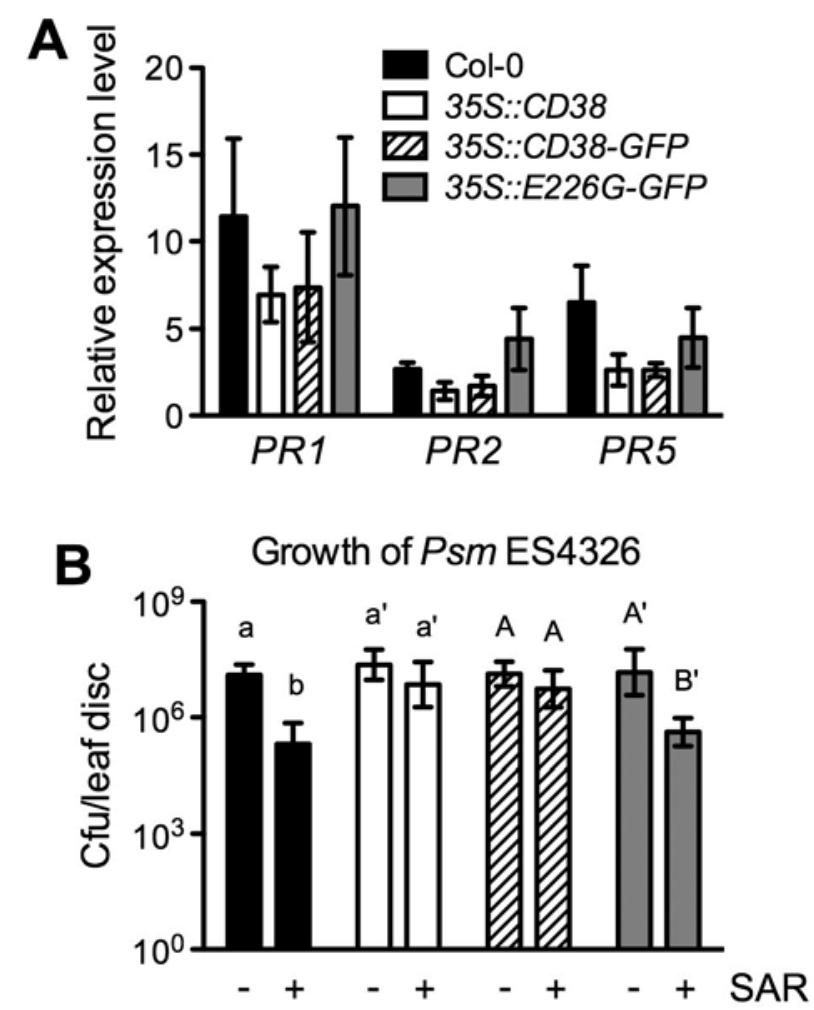

Fig. 6. Suppression of biological induction of systemic acquired resistance (SAR) by CD38. A, Expression of $P R 1, P R 2$, and $P R 5$ in the systemic leaves of wild-type Col-0, 35S::CD38, 35S::CD38- GFP, and $35 S::$ E226G-GFP plants with lower leaves infected with Pst/avrRpt2 (optical density at $600 \mathrm{~nm}\left[\mathrm{OD}_{600}\right]=0.002$ ). B, Growth of Pseudomonas syringae pv. maculicola ES4326 in the systemic leaves of wild-type Col-0, 35S::CD38, 35S::CD38-GFP, and 35S::E226G-GFP plants with lower leaves either infected with Pst/avrRpt2 $\left(\mathrm{OD}_{600}=0.002\right)(+\mathrm{SAR})$ or not infected (-SAR). Error bars represent standard deviation, and different letters above the bars indicate significant differences $(P<0.05, t$ test $)$. The experiment was repeated three times with similar results.
GTTGCAAATTATGGACTCCCACACTCCCAAAAGTG-3'). The presence of the expected mutation in the resulting construct was verified by DNA sequencing. A pair of primersSal I-CD38F (5'-ACGCGTCGACATGGCCAACTGCGAGTT CAG-3') and Sac I-CD38R (5'-CGAGCTCTCAGATCTCAGA TGTGCAAGATG-3') — was used to amplify the coding region of $C D 38$ from the cDNA clone of $C D 38$. The PCR products were digested with $S a l \mathrm{I}$ and $\mathrm{SacI}$ and then ligated into the corresponding sites of the vector pBI1.4T, resulting in the plasmid pBI1.4T-35S::CD38. The plasmids were introduced into Agrobacterium GV3101(pMP90) by electroporation, and plant transformation was performed following the floral dip method (Bent 2000).

\section{Chemical treatment and pathogen infection.}

NADPH-Na, NADP-Na, NADH-Na, NAD-Na, and ATP-Na were dissolved in water, and the $\mathrm{pH}$ of the resulting solutions were adjusted to approximately 6.0 with $0.1 \mathrm{M} \mathrm{NaOH}$. The solution was infiltrated into Arabidopsis leaves with a 1-ml syringe. For $P R$ gene expression, the infiltrated leaves were collected for RNA extraction $24 \mathrm{~h}$ after the treatment. For disease resistance test, the infiltrated leaves were inoculated with bacterial pathogens $5 \mathrm{~h}$ after the treatment. Infection of plants with $P$. syringae pv. maculicola ES4326 was performed as described previously (Zhang et al. 2007). Briefly, Arabidopsis leaves were infiltrated with $\mathrm{NADPH}, \mathrm{NADP}^{+}, \mathrm{NADH}, \mathrm{NAD}^{+}$, ATP, or $\mathrm{MgCl}_{2}$. After $5 \mathrm{~h}$, the infiltrated leaves were inoculated with the bacterial pathogen ES4326 (optical density at $600 \mathrm{~nm}$ $\left[\mathrm{OD}_{600}\right]=0.001$ ). Eight leaves were collected 2 or 3 days postinoculation to examine the growth of the pathogen. For cADPR and NAADP treatment, Arabidopsis leaves were infiltrated with cADPR and NAADP dissolved in $10 \mu \mathrm{M}$ sodium phosphate buffer ( $\mathrm{pH} 7.0$ ). After $5 \mathrm{~h}$, the infiltrated leaves were inoculated with the bacterial pathogen Pst/avrRpt2 $\left(\mathrm{OD}_{600}=0.002\right)$ for SAR induction.

\section{Ion leakage measurement.}

For each treatment or genotype, 20 leaf disks (approximately $7 \mathrm{~mm}$ in diameter) were removed 10 min after pathogen infiltration and washed twice with distilled water for a total of $50 \mathrm{~min}$; then, sets of five leaf disks each were placed in $6 \mathrm{ml}$ of fresh water in a test tube. Conductance of the water was measured over time with an Orion 3 Star portable conductivity meter (Thermo Electron Corporation, Beverly, MA, U.S.A.).

RNA and protein analysis.

RNA extraction and RNA gel blot analysis were carried out as described by Cao and associates (1997). Reverse-transcription and quantitative PCR were performed as previously described (Defraia et al. 2010). Protein gel-blot analysis was performed as previously described (Mou et al. 2000).

\section{Membrane fractionation.}

Total membrane proteins were obtained by homogenization of $5 \mathrm{~g}$ of leaf tissue in extraction buffer $(250 \mathrm{mM}$ Tris- $\mathrm{HCl}[\mathrm{pH}$ 8.5], $290 \mathrm{mM}$ sucrose, $25 \mathrm{mM}$ EDTA, and $5 \mathrm{mM} \beta$-mercaptoethanol; and protease inhibitors $N$-tosyl-L-phenylalanine chloromethyl ketone at $50 \mu \mathrm{g} \mathrm{ml} \mathrm{m}^{-1}$, 1-chloro-3-tosylamido-7amino-L-2-heptanone at $50 \mu \mathrm{g} \mathrm{ml} \mathrm{m}^{-1}$, and $0.6 \mathrm{mM}$ phenylmethylsulfonyl fluoride) with a mortar and pestle on ice. The homogenate was filtered through cheesecloth and centrifuged at $10,000 \times g$ for $10 \mathrm{~min}$ at $4^{\circ} \mathrm{C}$. The supernatant (crude lysate) was then centrifuged at $100,000 \times g$ for $2 \mathrm{~h}$ at $4^{\circ} \mathrm{C}$. The supernatant of this spin was the soluble fraction and the pellet was resuspended in sodium dodecyl sulfate polyacrylamide gel electrophoresis buffer to form the membrane fraction and subject to protein gel immunoblot analysis. 
Collection of EWF and pyridine nucleotide assay.

EWF was collected as described by Ogawa and associates (1996). Briefly, leaves were inoculated with the bacterial pathogen Pst/avrRpt2 $\left(\mathrm{OD}_{600}=0.02\right)$. When the leaves started to become water soaked (approximately $14 \mathrm{~h}$ after the inoculation), they were detached and rinsed three times with water, then dipped in water and subjected to vacuum infiltration. After infiltration, water on the surface of the leaves was carefully removed with paper tissues. The infiltrated water was then collected by centrifugation of the leaves at $500 \times g$ for $5 \mathrm{~min}$, and designated as the EWF. The EWF was immediately subjected to the pyridine nucleotide assay. For each treatment, 108 leaves (approximately $2 \mathrm{~g}$ ) were used. Pyridine nucleotide assay was performed as previously described (Zhang and Mou 2009). For total NAD and NADP assay, $100 \mathrm{mg}$ of tissue was ground into fine powder in liquid nitrogen. For undenatured samples, $1 \mathrm{ml}$ of extraction buffer $(10 \mathrm{mM}$ Tris- $\mathrm{HCl}, \mathrm{pH} 7.0)$ was added to the powder and the mixture was incubated at room temperature for $5 \mathrm{~min}$. For denatured samples, $1 \mathrm{ml}$ of extraction buffer preheated to $95^{\circ} \mathrm{C}$ was added to the powder and the mixture was incubated at $95^{\circ} \mathrm{C}$ for $5 \mathrm{~min}$. After brief vortexing and centrifugation at $16,000 \times g$ for $5 \mathrm{~min}$ at $4^{\circ} \mathrm{C}$, the supernatants were immediately subjected to the pyridine nucleotide assay.

\section{Microscopy.}

Confocal microscopy was performed as described previously (Mou et al. 2003). Protoplasts were produced as described (Zhang and Mou 2009). Propidium iodide staining and plasmolysis were performed as described by Libault and associates (2010). Briefly, 5-day-old Arabidopsis seedling roots were stained in a propidium iodide water solution $\left(5 \mu \mathrm{g} \mathrm{ml}^{-1}\right)$ for $1 \mathrm{~min}$, rinsed with distilled water, and visualized using an excitation wavelength of $543 \mathrm{~nm}$ and a 565- to 615-nm emission filter. For plasmolysis, roots were incubated for $10 \mathrm{~min}$ in $1 \mathrm{M} \mathrm{NaCl}$ solution prior to observation.

\section{Statistical methods.}

All statistical analyses were performed with the data analysis tools ( $t$ test: two samples assuming unequal variances) in Microsoft Excel of Microsoft Office 2004 for Macintosh.

\section{ACKNOWLEDGMENTS}

We thank C. An for comments on the manuscript, A. Yen (Cornell University) for providing the human CD38 cDNA clone, G. Stacey (University of Missouri) for helping with analysis of protein subcellular localization, and Y. Mou for generating the pCB302-35S::CD38-GFP and pCB30235S::E226G-GFP construct. This work was supported by grants from the National Science Foundation (NSF IOS-0842716) and from the Herman Frasch Foundation for Chemical Research (HFFCR) awarded to Z. Mou.

\section{LITERATURE CITED}

Alvarez, M. E., Pennell, R. I., Meijer, P.-J., Ishikawa, A., Dixon, R. A., and Lamb, C. 1998. Reactive oxygen intermediates mediate a systemic signal network in the establishment of plant immunity. Cell 92:773-784.

Attaran, E., Zeier, T. E., Griebel, T., and Zeierb, J. 2009. Methyl salicylate production and jasmonate signaling are not essential for systemic acquired resistance in Arabidopsis. Plant Cell 21:954-971.

Bannas, P., Adriouch, S., Kahl, S., Braasch, F., Haag, F., and Koch-Nolte, F. 2005. Activity and specificity of toxin-related mouse T cell ectoADP-ribosyltransferase ART2.2 depends on its association with lipid rafts. Blood 105:3663-3670.

Bent, A. F. 2000. Arabidopsis in planta transformation. Uses, mechanisms, and prospects for transformation of other species. Plant Physiol. 124:1540-1547.

Berger, F., Ramirez-Hernandez, M. H., and Ziegler, M. 2004. The new life of a centenarian: Signalling functions of NADP. Trends Biochem. Sci. 29:111-118.

Billington, R. A., Bellomo, E. A., Floriddia, E. M., Erriquez, J., Distasi, C., and Genazzani, A. A. 2006a. A transport mechanism for NAADP in a rat basophilic cell line. FASEB (Fed. Am. Soc. Exp. Biol.) J. 20:521523.

Billington, R. A., Bruzzone, S., De Flora, A., Genazzani, A. A., KochNolte, F., Ziegler, M., and Zocchi, E. 2006b. Emerging functions of extracellular pyridine nucleotides. Mol. Med. 12:324-327.

Bruzzone, S., Guida, L., Zocchi, E., Franco, L., and De Flora, A. 2001. Connexin 43 hemi channels mediate $\mathrm{Ca}^{2+}$-regulated transmembrane $\mathrm{NAD}^{+}$fluxes in intact cells. FASEB (Fed. Am. Soc. Exp. Biol.) J. 15:10-12.

Cao, H., Glazebrook, J., Clark, J. D., Volko, S., and Dong, X. 1997. The Arabidopsis NPR1 gene that controls systemic acquired resistance encodes a novel protein containing ankyrin repeats. Cell 88:57-63.

Ceni, C., Pochon, N., Brun, V., Muller-Steffner, H., Andrieux, A., Grunwald, D., Schuber, F., De Waard, M., Lund, F., Villaz, M., and Moutin, M. J. 2003. CD38-dependent ADP-ribosyl cyclase activity in developing and adult mouse brain. Biochem. J. 370:175-183.

Chanda, B., Xia, Y., Mandal, M. K., Yu, K., Sekine, K. T., Gao, Q. M., Selote, D., Hu, Y., Stromberg, A., Navarre, D., Kachroo, A., and Kachroo, P. 2011. Glycerol-3-phosphate is a critical mobile inducer of systemic immunity in plants. Nat. Genet. 43:421-427.

Chaturvedi, R., Krothapalli, K., Makandar, R., Nandi, A., Sparks, A.A., Roth, M. R., Welti, R., and Shah, J. 2008. Plastid $\omega 3$-fatty acid desaturase-dependent accumulation of a systemic acquired resistance inducing activity in petiole exudates of Arabidopsis thaliana is independent of jasmonic acid. Plant J. 54:106-117.

Chivasa, S., Ndimba, B. K., Simon, W. J., Lindsey, K., and Slabas, A. R. 2005. Extracellular ATP functions as an endogenous external metabolite regulating plant cell viability. Plant Cell 17:3019-3034.

Chivasa, S., Murphy, A. M., Hamilton, J. M., Lindsey, K., Carr, J. P., and Slabas, A. R. 2009. Extracellular ATP is a regulator of pathogen defense in plants. Plant J. 60:436-448.

Coll, N. S., Epple, P., and Dangl, J. L. 2011. Programmed cell death in the plant immune system. Cell Death Differ. 18:1247-1256.

Contreras, J. E., Saez, J. C., Bukauskas, F. F., and Bennett, M. V. 2003. Gating and regulation of connexin $43 \mathrm{Cx} 43$ hemichannels. Proc. Natl. Acad. Sci. U.S.A. 100:11388-11393.

Dangl, J. L., and Jones, J. D. G. 2001. Plant pathogens and integrated defence responses to infection. Nature 411:826-833.

Deaglio, S., and Malavasi, F. 2006. The CD38/CD157 mammalian gene family: An evolutionary paradigm for other leukocyte surface enzymes. Purinergic Signal 2:431-441.

De Flora, A., Zocchi, E., Guida, L., Franco, L., and Bruzzone, S. 2004. Autocrine and paracrine calcium signaling by the CD38/NAD ${ }^{+} /$cyclic ADP-ribose system. Ann. N. Y. Acad. Sci. 1028:176-191.

Defraia, C. T., Zhang, X., and Mou, Z. 2010. Elongator subunit 2 is an accelerator of immune responses in Arabidopsis thaliana. Plant $\mathrm{J}$. 64:511-523.

Denu, J. M. 2003. Linking chromatin function with metabolic networks: Sir2 family of $\mathrm{NAD}^{+}$-dependent deacetylases. Trends Biochem. Sci. 28:41-48.

Devadas, S. K., and Raina, R. 2002. Preexisting systemic acquired resistance suppresses hypersensitive response-associated cell death in Arabidopsis hrll mutant. Plant Physiol. 128:1234-1244.

Durner, J., Wendehenne, D., and Klessig, D. F. 1998. Defense gene induction in tobacco by nitric oxide, cyclic GMP, and cyclic ADP-ribose. Proc. Natl. Acad. Sci. U.S.A. 95:10328-10333.

Durrant, W. E., and Dong, X. 2004. Systemic acquired resistance. Annu. Rev. Phytopathol. 42:185-209.

Galione, A., and Churchill, G. C. 2000. Cyclic ADP ribose as a calciummobilizing messenger. Sci. STKE 41:pe1.

Gomez-Gomez, L., Felix, G., and Boller, T. 1999. A single locus determines the sensitivity to bacterial flagellin in Arabidopsis thaliana. Plant J. 18:277-284.

Han, M. K., Cho, Y. S., Kim, Y. S., Yim, C. Y., and Kim, U. H. 2000. Interaction of two classes of ADP-ribose transfer reactions in immune signaling. J. Biol. Chem. 275:20799-20805.

He, S.-Y. 1998. Type III secretion systems in plant and animal pathogenic bacteria. Annu. Rev. Phytopathol. 36:363-392.

Heath, M. C. 2000. Hypersensitive response-related death. Plant Mol. Biol. 44:321-334.

Heidemann, A. C., Schipke, C. G., and Kettenmann, H. 2005. Extracellular application of nicotinic acid adenine dinucleotide phosphate induces $\mathrm{Ca}^{2+}$ signaling in astrocytes in situ. J. Biol. Chem. 280:35630-35640.

Jones, D. A., and Takemoto, D. 2004. Plant innate immunity-direct and indirect recognition of general and specific pathogen-associated molecules. Curr. Opin. Immunol. 16:48-62.

Judkins, C. P., Sobey, C. G., Dang, T. T., Miller, A. A., Dusting, G. J., and Drummond, G. R. 2006. NADPH-induced contractions of mouse aorta do not involve NADPH oxidase: A role for P2X receptors. J. Pharmacol. Exp. Ther. 317:644-650. 
Jung, H. W., Tschaplinski, T. J., Wang, L., Glazebrook, J., and Greenberg, J. T. 2009. Priming in systemic plant immunity. Science 324:89-91.

Krebs, C., Adriouch, S., Braasch, F., Koestner, W., Leiter, E. H., Seman, M., Lund, F. E., Oppenheimer, N., Haag, F., and Koch-Nolte, F. 2005. CD38 controls ADP-ribosyltransferase-2-catalyzed ADP-ribosylation of T cell surface proteins. J. Immunol. 174:3298-3305.

Kunkel, B. N., Bent, A. F., Dahlbeck, D., Innes, R. W., and Staskawicz, B. J. 1993. RPS2, an Arabidopsis disease resistance locus specifying recognition of Pseudomonas syringae strains expressing the avirulence gene avrRpt2. Plant Cell 5:865-875.

Lee, H. C. 2001. Physiological functions of cyclic ADP-ribose and NAADP as calcium messengers. Annu. Rev. Pharmacol. Toxicol. 41:317-345.

Libault, M., Zhang, X.-C., Govindarajulu, M., Qiu, J., Ong, Y. T., Brechenmacher, L., Berg, R. H., Hurley-Sommer, A., Taylor, C. G., and Stacey, G. 2010. A member of the highly conserved $F W L$ (tomato $F W 2$.2-like) gene family is essential for soybean nodule organogenesis. Plant J. 62:852-864.

Malavasi, F., Deaglio, S., Ferrero, E., Funaro, A., Sancho, J., Ausiello, C. M., Ortolan, E., Vaisitti, T., Zubiaur, M., Fedele, G., Aydin, S., Tibaldi, E. V., Durelli, I., Lusso, R., Cozno, F., and Horenstein, A. L. 2006. CD38 and CD157 as receptors of the immune system: A bridge between innate and adaptive immunity. Mol. Med. 12:334-341.

Malavasi, F., Deaglio, S., Funaro, A., Ferrero, E., Horenstein, A. L., Ortolan, E., Vaisitti, T., and Aydin, S. 2008. Evolution and function of the ADP ribosyl cyclase/CD38 gene family in physiology and pathology. Physiol. Rev. 88:841-886.

Martin, G. B., Bogdanove, A.J., and Sessa, G. 2003. Understanding the functions of plant disease resistance proteins. Annu. Rev. Plant Biol. 54:23-61.

Mishina, T., and Zeier, J. 2007. Pathogen-associated molecular pattern recognition rather than development of tissue necrosis contributes to bacterial induction of systemic acquired resistance in Arabidopsis. Plant J. 50:500-513

Morabito, F., Damle, R. N., Deaglio, S., Keating, M., Ferrarini, M., and Chiorazzi, N. 2006. The CD38 ectoenzyme family: Advances in basic science and clinical practice. Mol. Med. 12:342-344.

Moreschi, I., Bruzzone, S., Nicholas, R. A., Fruscione, F., Sturla, L., Benvenuto, F., Usai, C., Meis, S., Kassack, M. U., Zocchi, E., and De Flora, A. 2006. Extracellular $\mathrm{NAD}^{+}$is an agonist of the human P2Y 11 purinergic receptor in human granulocytes. J. Biol. Chem. 281:3141931429.

Mou, Z., He, Y., Dai, Y., Liu, X., and Li, J. 2000. Deficiency in fatty acid synthase leads to premature cell death and dramatic alterations in plant morphology. Plant Cell 12:405-418.

Mou, Z., Fan, W., and Dong, X. 2003. Inducers of plant systemic acquired resistance regulate NPR1 function through redox changes. Cell 113:935944

Munshi, C., Aarhus, R., Graeff, R., Walseth, T. F., Levitt, D., and Lee, H C. 2000. Identification of the enzymatic active site of CD38 by sitedirected mutagenesis. J. Biol. Chem. 275:21566-21571.

Mur, L. A., Kenton, P., Lloyd, A. J., Ougham, H., and Prats, E. 2008. The hypersensitive response; the centenary is upon us but how much do we know? J. Exp. Bot. 59:501-520.

Nemoto, E., Yu, Y., and Dennert, G. 1996. Cell surface ADP-ribosyltransferase regulates lymphocyte function-associated molecule-1 LFA-1 function in T cells. J. Immunol. 157:3341-3349.

Noctor, G., Queval, G., and Gakiere, B. 2006. NADP synthesis and pyridine nucleotide cycling in plants and their potential importance in stress conditions. J. Exp. Bot. 57:1603-1620.

Nurnberger, T., Brunner, F., Kemmerling, B., and Piater, L. 2004. Innate immunity in plants and animals: Striking similarities and obvious dif- ferences. Immunol. Rev. 198:249-266.

Odell, J. T., Nagy, F., and Chua, N. H. 1985. Identification of DNA sequences required for activity of the cauliflower mosaic virus $35 \mathrm{~S}$ promoter. Nature 313:810-812.

Ogawa, K., Kanematsu, S., and Asada, K. 1996. Intra- and extra-cellular localization of "cytosolic" CuZn-superoxide dismutase in spinach leaf and hypocotyl. Plant Cell Physiol. 37:790-799.

Park, S. W., Kaimoyo, E., Kumar, D., Mosher, S., and Klessig, D. F. 2007. Methyl salicylate is a critical mobile signal for plant systemic acquired resistance. Science 318:113-116.

Parker, J. E. 2009. The quest for long-distance signals in plant systemic immunity. Sci. Signal. 2:pe31.

Partida-Sanchez, S., Randall, T. D., and Lund, F. E. 2003. Innate immunity is regulated by CD38, an ecto-enzyme with ADP-ribosyl cyclase activity. Microbes Infect. 5:49-58.

Partida-Sanchez, S., Rivero-Nava, L., Shi, G., and Lund, F. E. 2007. CD38: An ecto-enzyme at the crossroads of innate and adaptive immune responses. Adv. Exp. Med. Biol. 590:171-183.

Rate, D. N., and Greenberg, J. T. 2001. The Arabidopsis aberrant growth and death2 mutant shows resistance to Pseudomonas syringae and reveals a role for NPR1 in suppressing hypersensitive cell death. Plant J. 27:203-211.

Ron, M., and Avni, A. 2004. The receptor for the fungal elicitor ethyleneinducing xylanase is a member of a resistance-like gene family in tomato. Plant Cell 16:1604-1615.

Ryals, J. A., Neuenschwander, U. H., Willits, M.G., Molina, A., Steiner, H.-Y., and Hunt, M. D. 1996. Systemic acquired resistance. Plant Cell 8:1809-1819.

Sanchez, J. P., Duque, P., and Chua, N. H. 2004. ABA activates ADPR cyclase and cADPR induces a subset of ABA-responsive genes in Arabidopsis. Plant J. 38:381-395.

Seman, M., Adriouch, S., Scheuplein, F., Krebs, C., Freese, D., Glowacki, G., Deterre, P., Haag, F., and Koch-Nolte, F. 2003. NAD-induced T cell death: ADP-ribosylation of cell surface proteins by ART2 activates the cytolytic $\mathrm{P}_{2} \mathrm{X}_{7}$ purinoceptor. Immunity 19:571-582.

Singaravelu, K., and Deitmer, J. W. 2006. Calcium mobilization by nicotinic acid adenine dinucleotide phosphate NAADP in rat astrocytes. Cell Calcium 39:143-153.

Smyth, L. M., Bobalova, J., Mendoza, M. G., Lew, C., and MutafovaYambolieva, V. N. 2004. Release of beta-nicotinamide adenine dinucleotide upon stimulation of postganglionic nerve terminals in blood vessels and urinary bladder. J. Biol. Chem. 279:48893-48903.

Truman, W., Bennett, M. H., Kubigsteltig, I., Turnbull, C., and Grant, M. 2007. Arabidopsis systemic immunity uses conserved defense signaling pathways and is mediated by jasmonates. Proc. Natl. Acad. Sci. U.S.A. 104:1075-1080.

Vlot, A. C., Klessig, D. F., and Park, S. W. 2008. Systemic acquired resistance: The elusive signals. Curr. Opin. Plant Biol. 11:436-442.

Wirthmueller, L., Zhang, Y., Jones, J. D., and Parker, J. E. 2007. Nuclear accumulation of the Arabidopsis immune receptor RPS4 is necessary for triggering EDS1-dependent defense. Curr. Biol. 17:2023-2029.

Zhang, X., and Mou, Z. 2008. Function of extracellular pyridine nucleotides in plant defense signaling. Plant Signal. Behav. 3:1143-1145.

Zhang, X., and Mou, Z. 2009. Extracellular pyridine nucleotides induce $P R$ gene expression and disease resistance in Arabidopsis. Plant $\mathrm{J}$. 57:302-312.

Zhang, X., Dai, Y., Xiong, Y., DeFraia, C., Li, J., Dong, X., and Mou, Z 2007. Overexpression of Arabidopsis MAP kinase kinase 7 leads to activation of plant basal and systemic acquired resistance. Plant $\mathrm{J}$. 52:1066-1079.

Zolkiewska, A. 2005. Ecto-ADP-ribose transferases: Cell-surface response to local tissue injury. Physiology 20:374-381. 